\title{
EVIDENCE OF TECTONIC RELEASE FROM UNDERGROUND NUCLEAR EXPLOSIONS IN LONG-PERIOD $S$ WAVES
}

\author{
By Terry C. Wallace, Donald V. Helmberger, and Gladys R. Engen
}

\begin{abstract}
The SH waves from 21 underground nuclear explosions at Pahute Mesa (NTS) were used to investigate tectonic release. The equivalent double-couple representation of the tectonic release, which was constrained by waveform modeling and the polarity of $S P$, is very similar for all the explosions. The average orientation is a right-lateral, strike-slip fault trending $\mathrm{N}^{1} 5^{\circ} \mathrm{W}$. Seismic moments were determined on the basis of comparisons with two western United States strike-slip earthquakes. BENHAM has the largest tectonic release moment $\left(5.6 \times 10^{24}\right.$ dyne$\mathrm{cm})$ and STILTON $\left(0.1 \times 10^{24}\right.$ dyne-cm) the smallest of the events studied. In general, the seismic moments increase with the size of the explosion, but the location of the explosion relative to previous explosions can strongly affect the tectonic release. The Pahute Mesa events can be separated into two populations: (1) events which are well separated (>4 km) from previous explosions, and (2) those events which are close $(<4 \mathrm{~km})$ to previous explosions. Those events which are close to previous explosions show a marked decrease in tectonic release. A least-squares fit of seismic moment to event size (as determined from the world wide, average $a b$ amplitude) shows that the two populations are approximately parallel, but offset. The fact that the trends remain separated even at small yields (e.g., PIPKIN and SCOTCH) suggests that for Pahute Mesa there is not a threshold for tectonic release. Since spatial position gives the best separation of high and low tectonic release events, a volume model is favored for the source mechanism. The preferred model is motion on a system of faults and joints.
\end{abstract}

\section{INTRODUCTION}

The presence of $S H$-wave type energy is a fairly common observation on the seismic records of many underground nuclear explosions. In fact, there are numerous examples for which the teleseismic Love waves are as large or larger than the Rayleigh waves. For large explosions not detonated in alluvium, the most popular theory for the existence of far-field transversely polarized waves is the release of preexisting stress (tectonic release). There are two basic models for this stress release: (1) the triggering of a dislocation on a nearby fault (Brune and Pomeroy, 1963; Aki et al., 1969; Aki and Tsai, 1972), and (2) stress relaxation from the highly fractured zone immediately around the detonation point (Press and Archambeau, 1972; Archambeau 1972). For either of the stress release models, the long-period teleseismic radiation pattern can be represented by an equivalent double-couple source. Determining the orientation of this double couple and quantifying the effects of shot depth and location on tectonic release are important problems for yield determination. In particular, when $M_{S}$ is used to estimate yield, poor azimuthal coverage could bias the estimate (von Seggern, 1970). In an earlier paper (Wallace et al., 1983), we showed that tectonic release occasionally has a strong signature on the long-period $P$ waves, and recent work (Murphy et al., 1983; Lay et al., 1984) has suggested that even the short-period $P$ waves could be influenced, thus, possibly biasing $m_{b}$.

Although surface wave analysis has provided the most evidence for tectonic 
release, it can rarely be used to determine a unique orientation for the equivalent double-couple source. This is because the Love wave radiation pattern for a vertical strike-slip fault and $45^{\circ}$ dip-slip fault (strike rotated $45^{\circ}$ from the strike-slip fault) is identical. Although the radiation pattern is the same for both fault orientations, the moments required to match the observed amplitudes is different by a factor of two. In addition, the two fault models would represent significantly different amounts of $P$-wave excitation, so if the effects of tectonic release on $m_{b}$ are to be resolved this ambiguity in source orientation is unacceptable. Rayleigh waves can add information only if the moment of the explosion is small compared to the tectonic release. Otherwise, it is possible to adjust the source depth and size of the tectonic release such that the combined explosion and tectonic release Rayleigh wave spectra are identical for the two fault models. Aki and Tsai (1972) document this for BOXCAR, BENHAM, and BILBY.

Clear $S$ waves are commonly observed on teleseismic long-period seismograms from large yield explosions on Pahute Mesa at NTS. Nuttli (1969) showed that the $S H$ radiation patterns for GREELEY and HALFBEAK are consistent with that of a double couple, but again the $S H$ waves have the same ambiguity as Love waves in terms of determining the source orientation. Hirasawa (1971) used the polarization angles of the $S$ waves from GREELEY, BOXCAR, and BENHAM in an attempt to determine the mechanism of the tectonic release associated with these events. Uncertainty in the size of the $p S$ phase from the explosion make Hirasawa's results nonunique, but he argues that the polarizations are best fit with vertical strike-slip faulting for the tectonic release, with a nearly north-south fault strike.

In an earlier paper (Wallace et al., 1983), we showed that many Pahute Mesa explosions have long-period $P$ waves at upper mantle distances which appear to be distorted by an $s P$ arrival. The size of $s P$ correlates directly with the excitation of Love waves and hence, tectonic release, suggesting that $s P$ and $S H$ energy are generated in the same process. In this paper we make use of the polarity of $s P$ and $\mathrm{SH}$ to constrain the tectonic release orientation from Pahute Mesa explosions. In addition, we determine the relative moments for the tectonic release for 21 Pahute Mesa events, and investigate the dependency of tectonic release on depth of burial and proximity to previous explosions.

\section{The $S$-WAVE OBSERvations}

At least some degree of Love wave excitation has been observed for most nuclear explosions since the initiation of the United States underground test program in the early 1960's, but it was not until 1966 and the detonation of GREELEY and HALFBEAK that there was clear identification of explosion generated $\mathrm{SH}$ at teleseismic distances. This is probably the result of two factors: (1) the relatively large yields of GREELEY and HALFBEAK as compared to their predecessors at NTS, and (2) the fact that they were located on Pahute Mesa rather than Yucca flats. As discussed by Toksöz and Kehrer (1972), it is apparent that given similar explosions a detonation at Pahute Mesa will usually have a larger tectonic release component than a detonation at Yucca Flats. Since 1966, there have been 19 other Pahute Mesa explosions in which we were able to identify a teleseismic $S H$ wave. This set of 21 Pahute Mesa explosions (see Table 1) provide an ideal data base to study tectonic release because they are spatially related (area of less than $300 \mathrm{~km}^{2}$ ), structurally related (mostly in Silent Valley Caldera), and have yields which range over an order of magnitude.

GREELEY has one of the most complete sets of $S H$ observations and shows a 
clear node and polarity reversal. Figure 1 is a summary of these observations. The polarity of stations FFC and RKON are reversed, indicating that the node is between $\mathrm{N} 43^{\circ} \mathrm{E}$ and $\mathrm{N} 25^{\circ} \mathrm{E}$. Shown below each observation is a synthetic $S H$ waveform or the $S H$ waveform observed for the 15 March 1979 Homestead Valley earthquake (JCT, DAL, SHA). The Homestead Valley event is a very shallow $(<4$ $\mathrm{km}$ ) vertical strike-slip earthquake (see the Appendix). The location of the Homestead event is such that it is about the same distance from the stations in the southeastern United States as NTS is from these same stations. The very strong similarity of the entire $\mathrm{SH}$ signals for GREELEY and a known shallow earthquake is strong evidence for a stress drop mechanism for tectonic release as opposed to source anisotropy or an unknown frequency-dependent mechanism. Also, note that the synthetic $S H$ waveforms, calculated for the Homestead Valley fault orientation,

TABLE 1

Tectonic Release from Pahute Mesa Explosions

\begin{tabular}{lcccccccc}
\hline \multicolumn{1}{c}{ Name } & Date & $\begin{array}{c}\text { Origin } \\
\text { Time }\end{array}$ & $\begin{array}{c}\text { Latitude } \\
\left({ }^{\circ} \mathrm{N}\right)\end{array}$ & $\begin{array}{c}\text { Longitude } \\
\left({ }^{\circ} \mathrm{N}\right)\end{array}$ & $\begin{array}{c}\text { Depth } \\
(\mathrm{km})\end{array}$ & $\begin{array}{c}m_{b} \\
\begin{array}{c}\text { Estimated } \\
\text { Yield } \\
(\mathrm{kt})\end{array}\end{array}$ & $\boldsymbol{M}_{\mathbf{0}} \times 10^{24}$ \\
\hline Almendro & $\mathbf{0 6 - 0 6 - 7 3}$ & $13: 00$ & 37.24 & 116.35 & $\mathbf{1 . 0 6 4}$ & 6.1 & 570 & 1.0 \\
Benham & $\mathbf{1 2 - 1 9 - 6 6}$ & $16: 30$ & 37.23 & 116.47 & 1.402 & 6.3 & 1000 & 5.6 \\
Boxcar & $04-26-68$ & $15: 00$ & 37.29 & 116.46 & $\mathbf{1 . 1 5 8}$ & 6.2 & 1000 & 1.4 \\
Camembert & $\mathbf{0 6 - 2 6 - 7 5}$ & $12: 30$ & 37.28 & 116.37 & 1.311 & 6.1 & 750 & 1.4 \\
Cheshire & $02-14-76$ & $11: 30$ & 37.24 & 116.42 & 1.167 & 5.8 & 350 & 0.7 \\
Colby & $03-14-75$ & $12: 30$ & 37.31 & 116.47 & 1.273 & 6.2 & 900 & 0.8 \\
Estuary & $03-09-76$ & $14: 00$ & 37.31 & 116.36 & 0.869 & 5.8 & 350 & 0.7 \\
Fontina & $02-12-76$ & $14: 45$ & 37.27 & 116.49 & 1.219 & 6.1 & 900 & 2.2 \\
Greeley & $12-20-66$ & $15: 30$ & 37.30 & 116.41 & 1.215 & 6.3 & 830 & 3.1 \\
Halfbeak & $06-30-66$ & $22: 15$ & 37.32 & 116.30 & 0.819 & 6.1 & 450 & 1.0 \\
Handley & $03-26-70$ & $19: 00$ & 37.30 & 116.53 & 1.206 & 6.4 & 1900 & 2.4 \\
Inlet & $11-20-75$ & $15: 00$ & 37.22 & 116.37 & 0.817 & 5.9 & 500 & 0.3 \\
Jorum & $09-16-69$ & $14: 30$ & 37.31 & 116.46 & 1.158 & 6.1 & 700 & 0.5 \\
Kasseri & $10-28-75$ & $14: 30$ & 37.29 & 116.41 & 1.265 & 6.2 & 1200 & 2.0 \\
Mast & $06-19-75$ & $13: 00$ & 37.35 & 116.32 & 0.912 & 5.9 & 520 & 0.5 \\
Muenster & $01-03-76$ & $19: 15$ & 37.30 & 116.33 & 1.451 & 6.2 & 600 & 3.2 \\
Pipkin & $10-08-69$ & $14: 30$ & 37.26 & 116.44 & 0.617 & 5.6 & 82 & 0.2 \\
Pool & $03-17-76$ & $14: 15$ & 37.26 & 116.31 & 0.879 & 6.0 & 500 & 0.2 \\
Scotch & $05-23-67$ & $14: 00$ & 37.27 & 116.37 & 0.978 & 5.7 & 140 & 0.3 \\
Stilton & $06-03-75$ & $14: 20$ & 37.34 & 116.52 & 0.731 & 5.8 & 275 & 0.1 \\
Tybo & $05-14-75$ & $14: 00$ & 37.22 & 116.47 & 0.765 & 5.9 & 380 & 0.3 \\
\hline
\end{tabular}

*From Dahlman and Israelson (1979).

do an adequate job of predicting the observed waveforms with the exception of FFC. The poor fit here is probably an indication that FFC is very near the node.

For most of the Pahute Mesa explosions, the $S H$ waveforms are remarkably similar. Figure 2 shows a comparison of the $S H$ waveforms for MUENSTER (top trace) and GREELEY (bottom trace). Note that there is a change in polarity in the MUENSTER waveforms between FFC and LHC indicating that there is a node between $\mathrm{N} 25^{\circ} \mathrm{E}$ and $\mathrm{N} 45^{\circ} \mathrm{E}$. The GREELEY and MUENSTER waveforms are essentially identical except at FFC; the GREELEY waveform appears to be more nodal, which suggests that the node for MUENSTER (and hence fault strike) is shifted slightly to the east.

The fact that there is a "characteristic" $S H$ waveform for most of the Pahute Mesa events indicates that the mechanism for tectonic release for all these events is very similar. For example, if we assume that the strike of the equivalent double 


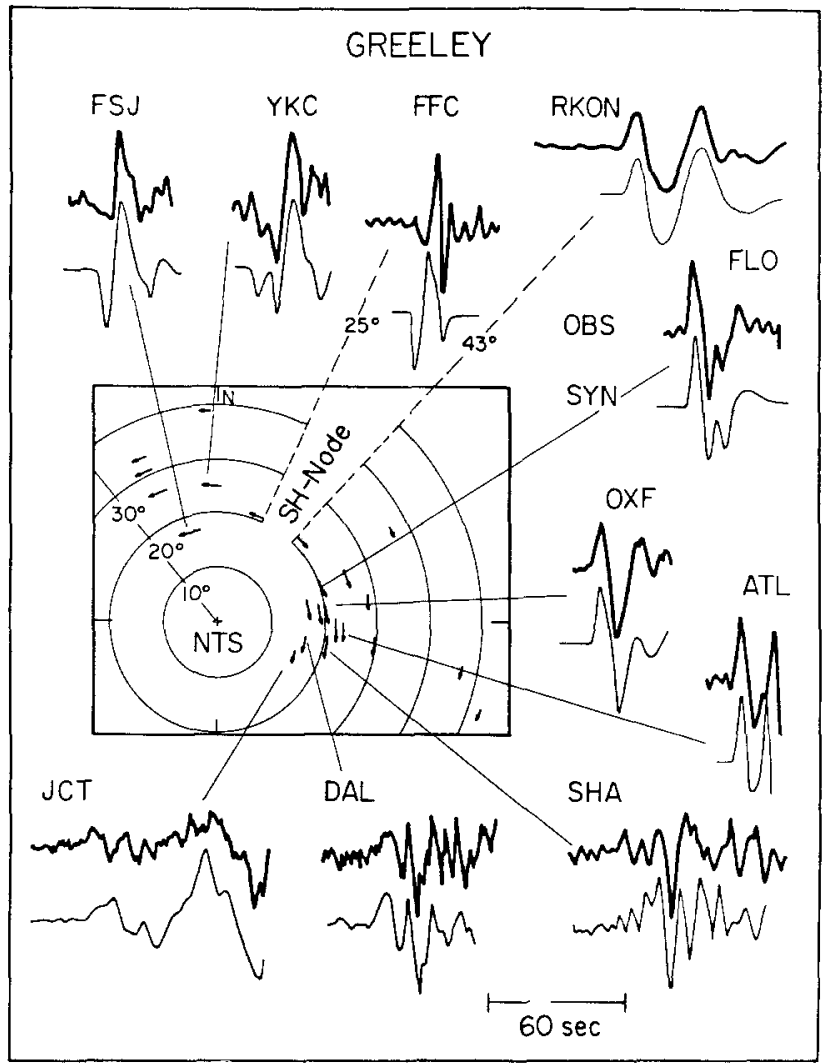

FIG. 1. The observed long-period $S H$ waveforms for the event GREELEY. The arrows indicate polarities of $S H$, and are located to indicate the distance and azimuth from NTS (see Nuttli, 1969). Shown below the observed waveforms are synthetics for a strike-slip model, or in the case of JCT, DAL, and SHA waveforms for the Homestead Valley earthquakes.

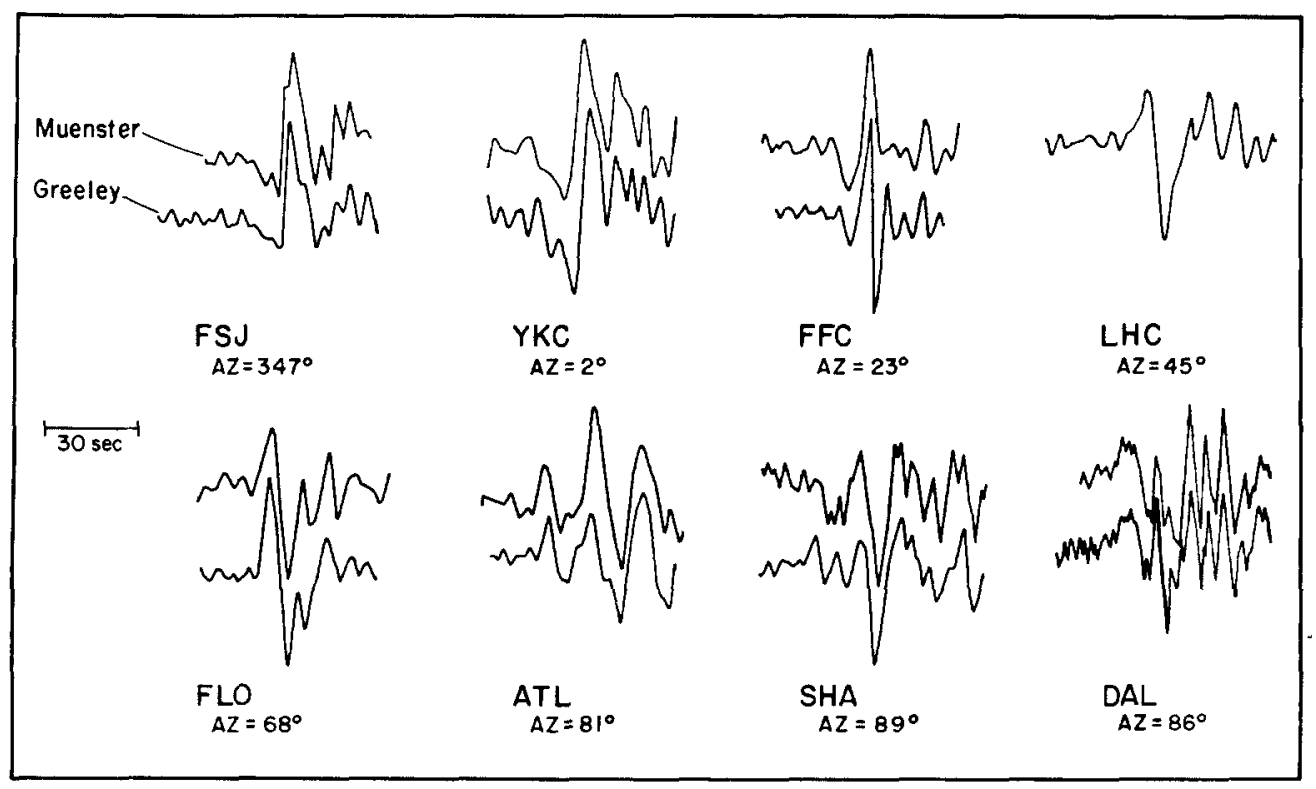

FIG. 2. Comparison between the $S H$ waveforms for GREELEY and MUENSTER (top trace). 
couple for the tectonic release from GREELEY is within $5^{\circ}$ of that for the tectonic release from MUENSTER then the comparison in Figure 2 indicates that the fault plane dips must be the same within $15^{\circ}$. If the variation in dip was larger than this then there would be signficant differences in the waveforms. This is consistent with the work of Toksöz and Kehrer (1972) who inverted Love/Rayleigh amplitude ratios for six Pahute Mesa explosions. Assuming a vertical strike-slip orientation for the tectonic release they showed that fault strike only varies by $10^{\circ}$. The fact that the tectonic release orientation appears to repeat itself for most of the Pahute Mesa events implies that the tectonic release is regionally controlled (where the "region" is Pahute Mesa or the Silent Valley caldera).

Assuming that the orientation of the tectonic release is the same for all the Pahute Mesa events, then it is possible to compare the $S H$ waveforms for many

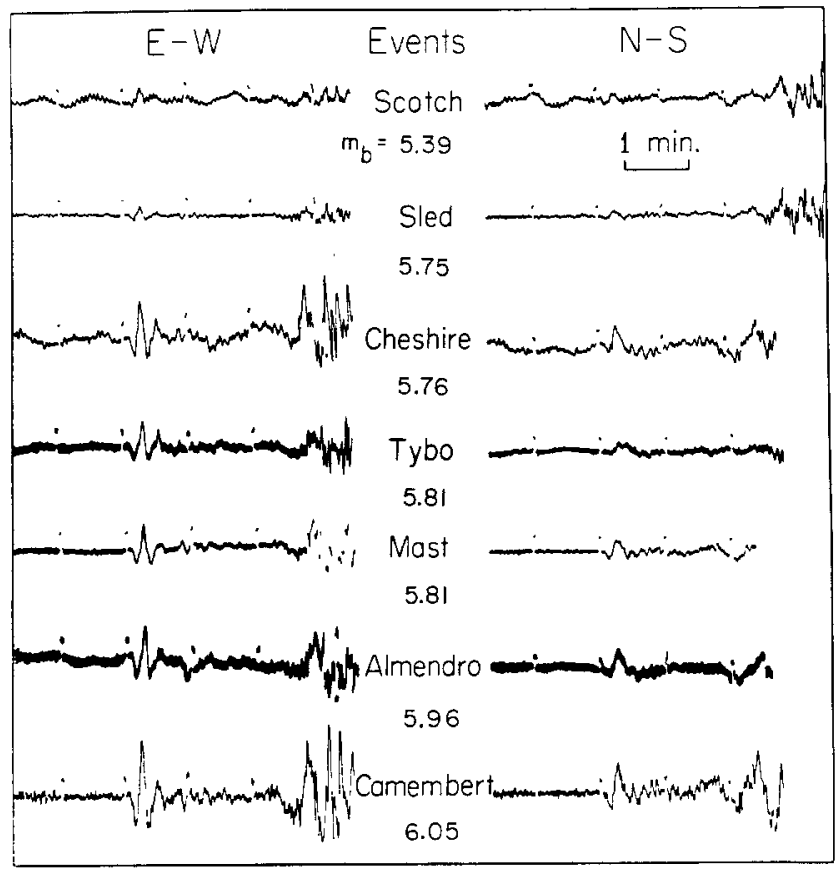

FIG. 3. The long-period horizontal seismograms at OXF for several Pahute Mesa explosions. The station is nearly naturally rotated so that the E-W represents the $S V$ and N-S is $S H$. The explosions are ordered on the basis of increasing world-wide, short-period $a b P$-wave amplitude.

events at a single station and determine the relative size of the tectonic release. Figure 3 shows the two long-period horizontal components at OXF $(\Delta=22.40)$ for seven different explosions. OXF is close to being naturally rotated (back azimuth $=274^{\circ}$ ) so the $\mathrm{N}-\mathrm{S}$ component is $S H$ while the $\mathrm{E}-\mathrm{W}$ is $S V$. All the records are at the same amplitude scale; CAMEMBERT has the largest $S H$ amplitude while SLED has the smallest. The explosions are ordered on the basis of $m_{b}$ as determined by Lay $e$ t al. (1984). Although there is considerable uncertainty in relating yield to $m_{b}$, it is reasonable to assume that the records in Figure 3 are ordered on the basis of yield. Figure 3 shows that although the $S H$ waveforms are similar for all the events, $S H$ amplitude does not increase simply with explosion size. TYBO and CHESHIRE have nearly the same $m_{b}$, but the CHESHIRE $S H$ wave is 3 times as large as the TYBO $S H$. In general, the $S V$ amplitude is less influenced by the tectonic release, although on the basis of a north-south, right-lateral strike-slip 
model for the tectonic release it would be predicted that the $S V$ from the explosion and tectonic release would constructively interfere at $\mathrm{OXF}$. This may explain the enhanced $S V$ for CHESHIRE as compared to TYBO, although CHESHIRE may have a large $\Delta m_{b}$. The $S V$ waveforms are very similar for all the events, and it is difficult to identify a signature of tectonic release on the basis of $S V$ alone at a single station.

\section{Constraints on the Mechanism of the Tectonic Release}

On the basis of $S H$ waves alone, it is impossible to constrain the orientation of the tectonic release, but the addition of information about the polarity of only a few $P$ waves can significantly restrict the possible fault orientations. Langston and Helmberger (1975) shows that the tangential component of surface displacement in the far-field produced by an arbitrarily oriented fault as a function of distance and azimuth can be expressed by

$$
V(r, \theta, t)=\frac{M_{0}}{4 \pi \rho} f(t) * \sum_{j=1}^{2} A j G j(t)
$$

where $M_{0}$ is the seismic moment, $\rho_{0}$ is the density of the source, $f(t)$ is the far-field time function and $G j$ are the Green's functions for a vertical strike-slip and a vertical dip-slip fault. The Green's functions are dependent on the source of receiver velocity and $Q$ structure. The $A j$ are coefficients determined by the fault orientation, and are given by

$$
\begin{aligned}
& A_{1}(\theta, \lambda, S)=\cos 2 \theta \cos \lambda \sin \delta-\frac{1}{2} \sin 2 \theta \sin \lambda \sin 2 \delta \\
& A_{2}(\theta, \lambda, \delta)=-\sin \theta \cos \lambda \sin \delta-\cos \theta \sin \lambda \cos 2 \delta
\end{aligned}
$$

where $\theta$ is the strike measured from the end of the fault, $\lambda$ is the slip angle, and $\delta$ is the dip of the fault. Note that for a vertical strike-slip fault $\left(\delta=90^{\circ}, \lambda=0^{\circ}\right), A_{1}=$ $\cos 2 \Theta, A_{2}=0$, and for a $45^{\circ}$ dip-slip fault $\left(\delta=45^{\circ}, \lambda=90^{\circ}\right), A_{1}=-1 / 2 \sin 2 \theta, A_{2}$ $=0$. Since both fault orientations only depend on a single Green's function, and have a $2 \theta$ dependency the waveforms for both models will be identical, although the strike will be shifted $45^{\circ}$ and the moment doubled.

Figure 4 is a comparison of the GREELEY and MUENSTER $S H$ waveforms with those of the Homestead Valley earthquake. For all the stations shown, the travel paths for NTS and Homestead Valley are nearly identical. Also shown in Figure 4 are the location of stations plotted on a focal sphere with the $S H$ nodal lines; the mechanism shown for the earthquake is described in the Appendix, and the mechanism shown for the GREELEY tectonic release is a vertical strike-slip with the same orientation as Homestead Valley. The shallow depth of the Homestead Valley earthquake makes this an ideal event for comparison since we expect the tectonic release to be shallow. It is apparent from Figure 4 that the time function associated with the earthquake is longer period than for the explosions, but nevertheless the coherence between explosion and earthquake $S H$ waveforms is good at all stations. Although the comparison cannot be used to distinguish between a strike-slip fault oriented N-S and a $45^{\circ}$ dip-slip fault striking $\mathrm{N} 45^{\circ} \mathrm{W}$, it indicates that the mechanism for tectonic release cannot deviate by a significant amount from either of these two choices. If there was a systematic breakdown in waveform 


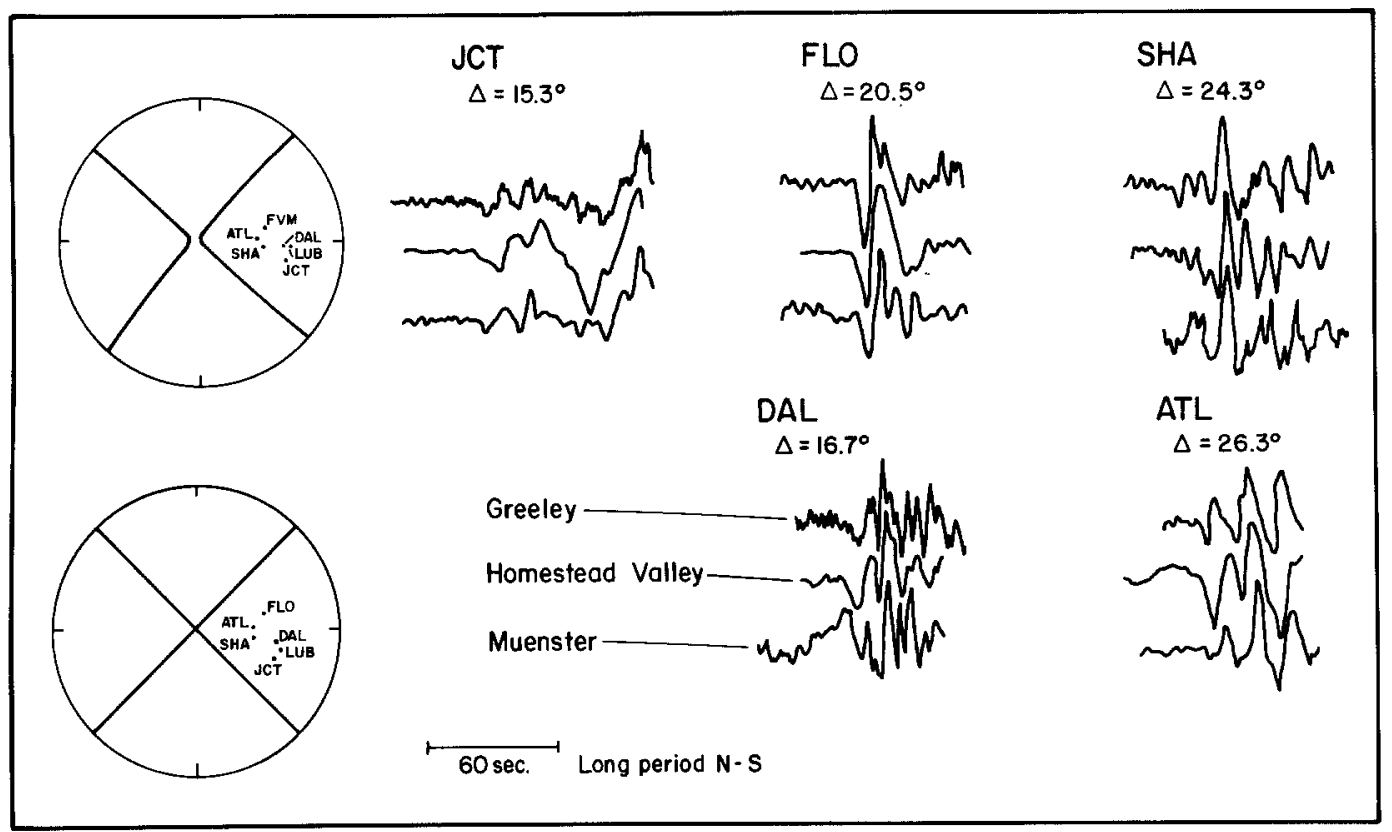

FIG. 4. A comparison of the GREELEY and MUENSTER $S H$ waveforms with those of the Homestead Valley earthquake (15 March 1979).

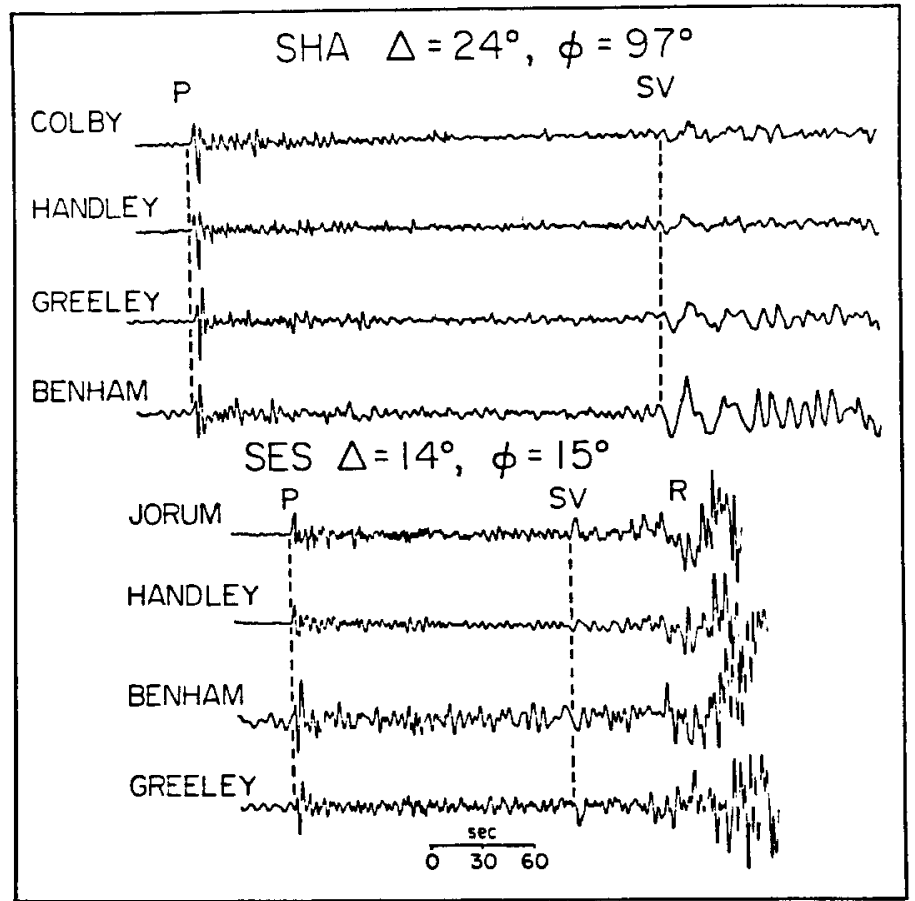

Frg. 5. Long-period vertical component recordings of several Pahute Mesa events from WWSSN station SHA and CSN station SES. Note that at SHA, the second upswing of the $P$ wave increases with increasing $S V$ amplitude. At SES the long-period $P$ waves show a more complicated pattern; for the large tectonic release events (BENHAM and GREELEY), the $S V$ and Rayleigh waves are actually reversed as compared to the low tectonic release events. 
fit (with either azimuth or epicentral distance), it would indicate that there is a deviation in either slip or dip angles from the two models.

Figure 5 shows the comparison of long-period vertical components for four explosions at two different stations. For the SHA records, note that the second upswing of the $P$ wave increases as the amplitude of the $S V$ increases. This strongly suggests that the second upswing of the $P$ wavetrain is controlled by an $S$ wave. Wallace et al. (1983) interpret this as the $s P$ phase from the tectonic phase. The explosions in Figure 5 are ordered on the basis of increasing tectonic release. At SES the $P$ waveform complexity is also related to a change in the $S V$ waveform. In this case as the complexity of $P$ waves increases (back swing), the $S V$ and Rayleigh wave actually reverse polarity. A direct comparison between the GREELEY and HANDLEY $P$ waveforms indicates that $s P$ also has a downward motion at SES. A similar comparison at SHA indicates that $s P$ has an upward polarity, implying that there is an $S V$ nodal line between SES and SHA.

On the basis of $S H$ waveforms and change in polarity of $s P$, we can construct three constraints on the orientation of the tectonic release: (1) the fault orientation must be approximately a vertical strike-slip or a $45^{\circ}$ dip-slip; (2) there must be an $\mathrm{SH}$ nodal line striking approximately $\mathrm{N} 30^{\circ} \mathrm{E}$; and (3) there must be nodal lines for $S V$ waves which separates SES and SHA. On the basis of these constraints, a three part search was used to examine the possible orientations. First the polarities of the $S H$ waveforms were fit. Note in Figure 1 that there are no nodal lines between $\mathrm{N} 30^{\circ} \mathrm{E}$ and $\mathrm{JCT}\left(\mathrm{N} 111^{\circ} \mathrm{E}\right)$, a quadrant of nearly $90^{\circ}$; this limits the solution space considerably. Next the proposed fault model must give a downward $s P$ first motion as SES but up at SHA. In addition, the $s P$ is a strong arrival at both stations. We generated a suite of synthetic $s P$ for the various fault models which fit the $S H$ polarities; most solutions with shallowing dipping planes $\left(<50^{\circ}\right)$ are immediately rejected on the basis of polarity. Figure 6 shows the $P$ waveforms for the three most different models: (1) vertical strike; (2) $45^{\circ}$ dipping thrust; and (3) $45^{\circ}$ dipping normal fault. Only (1) has the correct $s P$ polarity at both stations. Also shown in Figure 6 is the absolute amplitude of the waveforms for a seismic moment of $1 \times$ $10^{24}$ dyne-cm. It is clear that the dip-slip faulting orientation results in substantially larger amplitudes. As an example of dependence of excitation on fault orientation Figure 7 shows a comparison of long-period $P$ waveforms for the Homestead Valley (15 March 1979), Oroville (8 January 1975), and Truckee (12 September 1966) California earthquakes at station BLA $\left(\Delta \sim 32^{\circ}\right)$. All the records shown have the same amplitude scale with gains given to the right. The Truckee and Oroville earthquakes have a similar moments $\left(8.3 \times 10^{24}\right.$ and $5.7 \times 10^{24}$ dyne-cm, respectively), source locations, and depths. Truckee is a strike-slip event while Oroville is a moderately dipping normal faulting event. In Figure 7, both earthquakes are in "loop" directions, yet the $P$ waves from Oroville are twice as large. The Truckee event can only be seen on a few very high gain teleseismic stations (as discussed by Burdick, 1977), while in contrast the Oroville event was observed by most WWSSN stations (Langston and Butler, 1976; Wallace and Helmberger 1982). From equation (2), it is possible to compare the $S H$ amplitudes expected for a vertical strike-slip and $45^{\circ}$ dip-slip model; for a given moment the $S H$ waves will be approximately twice as large for the strike-slip case. This implies that if we use a dip-slip fault to model the $S H$ waveforms, the moment which we will determine will be twice as large as the case of assuming strike-slip tectonic release. Further, this will result in $P$ waveforms which are a factor of 4 larger than for the strike-slip model. Note in Figure 7 that GREELEY does not have a long-period $P$ wave signature. The fact 


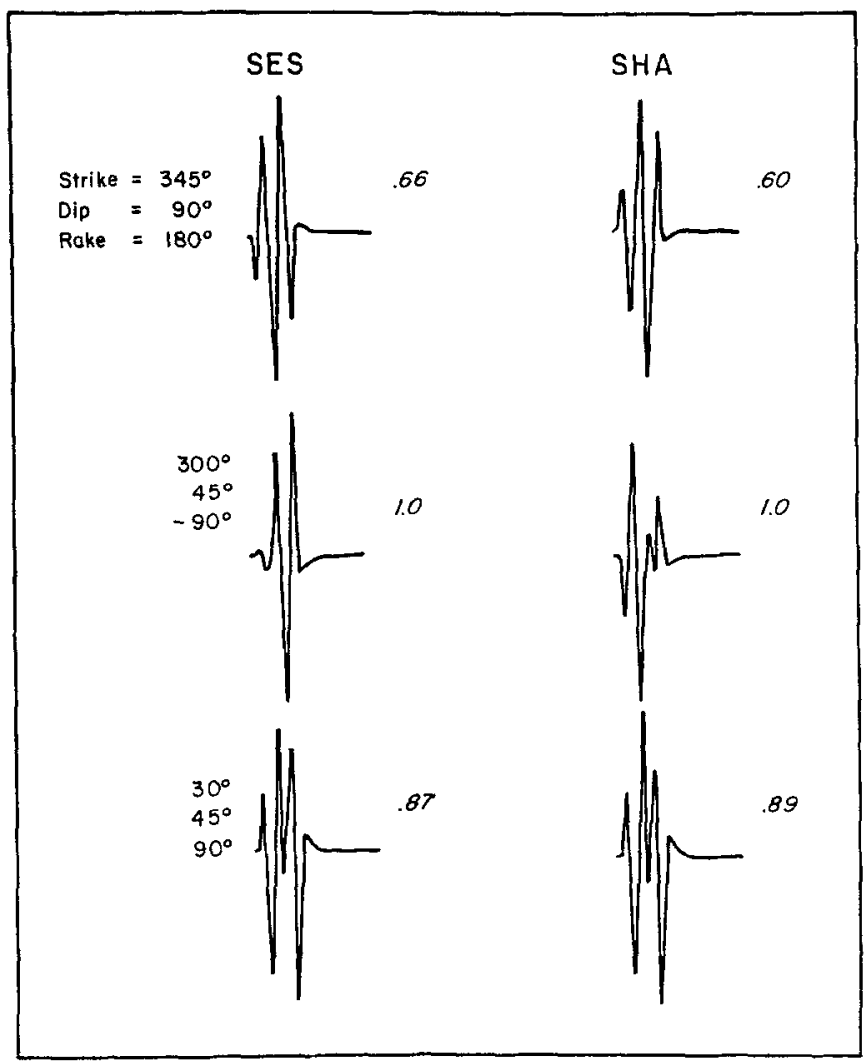

FIG. 6. A comparison of the $P$ waveforms for three different fault models. Shown to the left are the maximum amplitudes.

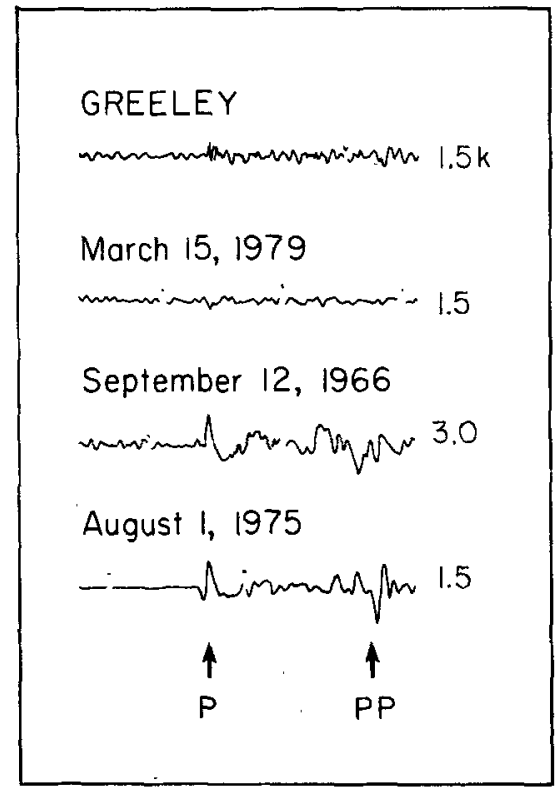

FiG. 7. A comparison of the long-period $P$ waveforms for the Oroville, Truckee and Homestead Valley earthquakes at station BLA. Also shown is the record from GREELEY. BLA is approximately $32^{\circ}$ from all the events; all the records are on the same amplitude scale, with the gains shown to the right. 
that short-period, teleseismic $P$ waveforms from tectonic release are not an often identified feature (Bache, 1976) further supports rejecting moderately dipping fault models.

The final step in determining possible fault orientations for the tectonic release was to generate $S H$ wave synthetics for the models which remained after the first two steps, and compare to the observed waveforms at YKC, FLO, and OXF. Severe differences in waveform fit result in rejecting a particular model. The only fault models which could satisfy all the criteria were predominantly strike-slip dislocations. The strike can vary from $\mathrm{N} 20^{\circ} \mathrm{W}$ to $\mathrm{N} 0^{\circ} \mathrm{E}$, the range in dips is vertical to $70^{\circ}$, and the acceptable slip angle is between $160^{\circ}$ and $200^{\circ}$. Figure 8 shows the focal mechanisms for the extreme solutions.

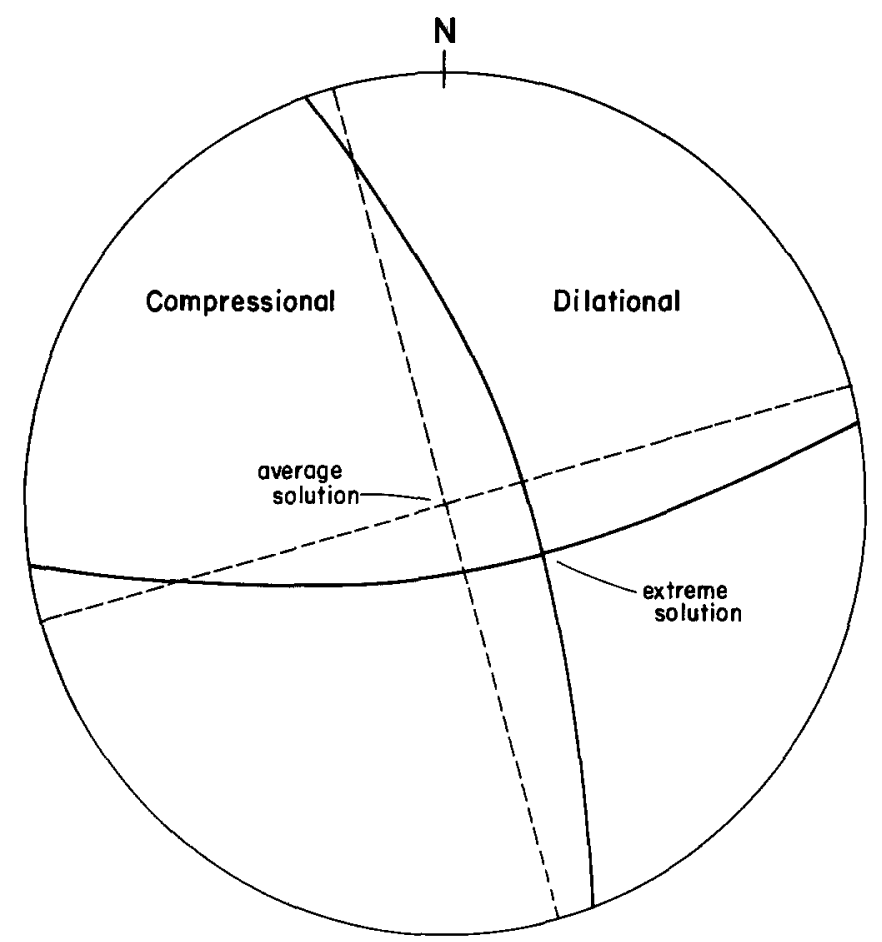

FIG. 8. The extreme focal mechanisms allowed for the average tectonic release from Pahute Mesa.

\section{TeCtonic Release Moments}

An observed teleseismic $S H$ waveform is a function both of the dislocation history on the fault and the structure of the travel path between the source and receiver. If these quantities are known, then equation (1) can be used to compute a synthetic $S H$ wave and a seismic moment can be determined simply by adjusting the amplitude of the synthetic to match that of the observed. Unfortunately most of the observed $\mathrm{SH}$ waveforms for tectonic release are at upper mantle distances $\left(14^{\circ}\right.$ to $\left.30^{\circ}\right)$ and in general the waveforms will change dramatically with distance due to triplications. Further, the structure is dependent on azimuth. The use of a single earth structure to model all the upper mantle records would result in wide variation in the moments determined. In particular, it is very difficult to determine the attenuation, and the assumption of a constant $t^{*}$ for the entire range in distances is undoubtably poor.

In an attempt to alleviate the problems of determining the complicated upper 
mantle velocity and $Q$ structure we determine the moments for the tectonic release on the basis of comparison of amplitudes with two earthquakes. The first of these earthquakes is the Homestead Valley event described earlier. The fault mechanism for this event is nearly identical with the "average" orientation for the tectonic release, and the Homestead epicenter is situated such that the travel paths to stations in the southeastern portion of the United States are nearly the same as those traveled from Pahute Mesa to the same stations. On the basis of comparison like those shown in Figure 4, it is possible to get an average ratio of $\mathrm{SH}$ amplitudes for six stations (JCT, DAL, OXF, FLO, SHA, and ATL). The ratios give the relative size of the tectonic release, and can be converted to seismic moments if something is known about the time function. A comparison of the $S H$ waves in Figure 3 suggests that although there is a factor of five variation in amplitude, there is little change in waveform shape or period. This is probably because the time function duration is short and the attenuation for $S$ waves is large; the attenuation is the factor which is controlling the period of the teleseismic waveforms. This implies that it is not possible to recover differences in the time function, so we assume that the time function is constant for all the tectonic release events. As a further simplification, we assume that the time function associated with the tectonic release is identical to the time function associated with the Homestead Valley earthquake.

The second earthquake we use to calibrate the moments of the $S H$ from the tectonic release occurred near the Nevada-Utah border on 16 August 1966 (see Wallace et al., 1983, for details about this event). This event is a right-lateral strikeslip event, with a strike about $\mathrm{N} 15^{\circ} \mathrm{E}$. The location of this event (near $200 \mathrm{~km}$ due east of NTS) allows favorable comparisons with the $S H$ waveforms from Pahute Mesa explosions recorded on northerly azimuths. CSN stations YKC $\left(\Delta=25.1^{\circ}\right)$, CMC $\left(\Delta=30.5^{\circ}\right)$, and $\mathrm{MBC}\left(\Delta=39.0^{\circ}\right)$ are almost exactly the same distance from the earthquake epicenter and Pahute Mesa. We determined the ratios of the $S H$ amplitudes for the different Pahute events as we did for the Homestead Valley earthquake and assumed a constant time function.

Table 1 is a list of seismic moments determined for the tectonic release for 21 explosions on Pahute Mesa. The moments were determined by comparing the $S H$ waveforms for both earthquakes described above, at a minimum of five stations. In addition, the maximum amplitude of the Love waves for all the explosions were compared as a check. The values for moment determined by comparison with each earthquake were averaged; these values differed by a factor of two in extreme cases. The variation in moment could be the result of two things. First, there is uncertainty in the moments determined for the earthquakes. The moment used for the Homestead Valley event is $1.9 \times 10^{24}$ dyne-cm as determined by regional distance body waves. This value is in close agreement with Dziewonski et al. (1984) who determined a moment of $2.2 \times 10^{24}$ dyne-cm from the inversion of 40 - to $80-\mathrm{sec}$ period mantle waves. The moment used for the Nevada border event is $4.1 \times 10^{24}$ dyne-cm determined from regional distance bodywaves (Wallace et al., 1983). Since the moments of the earthquakes are used as calibration, any error in their value will be translated to error in the tectonic release moment. A second possible source of error comes from the inability to resolve the time function. If either of the earthquakes were enriched in high frequencies, one would expect that moments based on the comparisons to differ. Because of the uncertainty in determining the moments, the numbers in Table 1 should be considered very good in a relative sense, and plus or minus 50 per cent in an absolute sense. 


\section{Discussion}

All the Pahute Mesa explosions studied here have some amount of tectonic release, and the mechanism for the tectonic release appears to be fairly consistent. On the basis of comparison of $S H$ wave data, the equivalent double couple is dominated by strike-slip motion. Although there is some variation in strike, dip, and rake, the "average" mechanism is a right-lateral strike-slip fault trending $\mathrm{N} 15^{\circ} \mathrm{W}$. These results are consistent with surface wave analysis (Toksöz and Kehrer, 1972; Aki and Tsai, 1972) in which a strike-slip mechanism is assumed. They are also consistent with Hirasawa (1971) and Nuttli (1969). Table 2 summarizes the previous results.

The strike-slip orientation of the tectonic release at Pahute Mesa is consistent with several indicators of the regional stress regime. The Massachusetts Mountain earthquake $\left(m_{b}=4.2\right)$ occurred about $40 \mathrm{~km}$ southwest of Pahute Mesa on 5 August 1971. The focal depth was determined to be $4.6 \mathrm{~km}$, and Fischer et al. (1972) used $P$-wave first motions to constrain the fault plane. The solution they obtained shows

TABLE 2

Orientation of Tectonic Release from Pahute Mesa EvENTS

\begin{tabular}{ccccc}
\hline Event & $\theta_{1}$ & $\Theta_{2}$ & $M_{0}\left(\times 10^{24}\right)$ & Reference $^{*}$ \\
\hline Benham & $\mathrm{N} 15^{\circ} \mathrm{W}$ & $\mathrm{N} 75^{\circ} \mathrm{E}$ & & 1 \\
& $\mathrm{~N} 6^{\circ} \mathrm{W}$ & $\mathrm{N} 84^{\circ} \mathrm{E}$ & $2-5$ & 2 \\
& $\mathrm{~N} 6^{\circ} \mathrm{W}$ & $\mathrm{N} 84^{\circ} \mathrm{E}$ & $1.4-2.3$ & 3 \\
Boxcar & & & & \\
& $\mathrm{N} 14^{\circ} \mathrm{W}$ & $\mathrm{N} 76^{\circ} \mathrm{E}$ & & 1 \\
& $\mathrm{~N} 12^{\circ} \mathrm{W}$ & $\mathrm{N} 78^{\circ} \mathrm{E}$ & 1.25 & 2 \\
& $\mathrm{~N} 25^{\circ} \mathrm{W}$ & $\mathrm{N} 65^{\circ} \mathrm{E}$ & $0.4-0.7$ & 3 \\
Greeley & $\mathrm{N} 5^{\circ} \mathrm{W}$ & $\mathrm{N} 85^{\circ} \mathrm{E}$ & & \\
& $\mathrm{N} 15^{\circ} \mathrm{W}-\mathrm{N} 15^{\circ} \mathrm{E}$ & $\mathrm{N} 75^{\circ} \mathrm{W}-\mathrm{N} 105^{\circ} \mathrm{E}$ & 4 \\
& $\mathrm{~N} 2^{\circ} \mathrm{W}$ & $\mathrm{N} 88^{\circ} \mathrm{E}$ & & 3 \\
Halfbeak & $\mathrm{N} 15^{\circ} \mathrm{W}$ & $\mathrm{N} 75^{\circ} \mathrm{E}$ & \\
& $\mathrm{N} 28^{\circ} \mathrm{W}-\mathrm{N} 3^{\circ} \mathrm{W}$ & $\mathrm{N} 62^{\circ} \mathrm{W}-\mathrm{N} 87^{\circ} \mathrm{E}$ & 1 \\
\hline
\end{tabular}

* 1, Toksöz and Kehrer (1972); 2, Aki and Tsai (1972); 3, Hirasawa (1971); 4, Nuttli (1969).

right-lateral strike-slip motion on a vertical fault striking $\mathrm{N} 22^{\circ} \mathrm{W}$. Patton (1982) inverted the short-period, regional distance Rayleigh waves for this event and found approximately the same orientation. The Nevada-Utah border earthquake (16 August 1966) used for the calibration of the $S H$ moments is about $200 \mathrm{~km}$ due east of Pahute Mesa. Again, this event is a near-vertical, right-lateral strike-slip earthquake, although the strike is somewhat shifted (N14 $\left.{ }^{\circ} \mathrm{E}\right)$. Finally, Hamilton and Healy (1969) reported that there were a large number of aftershocks for the event BENHAM which had right-lateral strike-slip mechanisms. The aftershocks were located southwest of ground zero, and were tightly aligned in a north south trend. Ryall and Savage (1969) also show that the aftershocks from BOXCAR are not symmetric about the explosion. The fact that the tectonic release orientation for the Pahute Mesa explosions consistently shows a strike-slip motion which agrees with the regional stress regime strongly indicates that the tectonic release is controlled by regional stresses. 
Aki and Tsai (1972) calculated moments for two of the events in this study (BENHAM and BOXCAR). They use the Love wave spectrum in the period band of 25 to $40 \mathrm{sec}$, and asssume a step function dislocation history. The moment Aki and Tsai obtain for BOXCAR $\left(1.25 \times 10^{24}\right.$ dyne-cm $)$ is in good agreement with this study $\left(1.4 \times 10^{24}\right.$ dyne-cm) although their moment for BENHAM $\left(2.5 \times 10^{24}\right.$ dyne$\mathrm{cm})$ is a factor of two smaller than in this study $\left(5.6 \times 10^{24}\right.$ dyne-cm). This is difficult to understand because the $S H$ waves from BENHAM are only slightly smaller than those observed for the 1966 Truckee earthquake $\left(m_{b}=5.6\right)$, which had a moment of $8 \times 10^{24}$ dyne-cm (Tsai and Aki, 1970). Also, on the basis of comparison with BOXCAR, BENHAM must be larger than by just a factor of two. For these reasons, we feel that our moment for BENHAM is correct. It is interesting to note that BENHAM has a tectonic release moment which is much larger than all the other Pahute Mesa events (see Table 1). If the BENHAM tectonic release were a $45^{\circ}$ dip-slip fault it would have moment of $10^{25}$ dyne-cm, and would result in a large $P$-wave signature teleseismically.

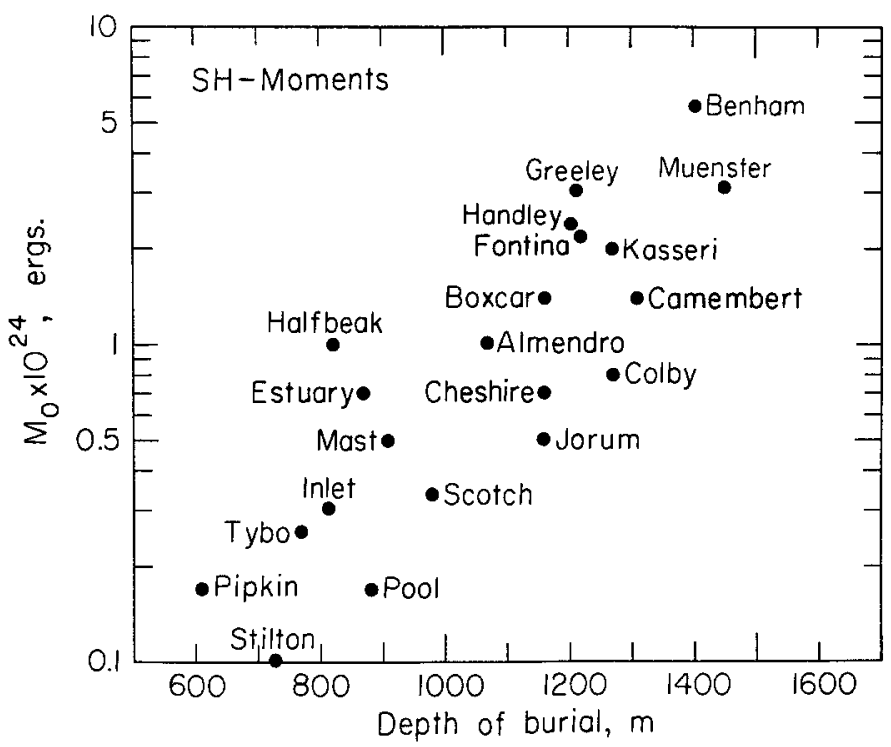

FIG. 9. The seismic moment of the tectonic release as determined from $S H$ and Love waves for 21 Pahute Mesa explosions plotted against depth of burial.

The 21 Pahute Mesa explosions provide an interesting data base to investigate tectonic release since there is an order of magnitude variation in both yield and seismic moment of the tectonic release. Figure 9 shows a plot of the moment of the tectonic release for these events against the depth of burial. There is a clear trend of moment increasing with burial depth, which is consistent with Aki and Tsai's (1972) findings for Yucca Flat events. Unfortunately, since there is a strong correlation between the depth of burial and yield it is difficult to separate these two effects on the basis of Figure 9 alone. There must be at least one other factor involved; for a depth of burial of approximately $1200 \mathrm{~m}$ there are six events with moments ranging from $0.5 \times 10^{24}$ dyne-cm (JORUM) to $3.1 \times 10^{24}$ dyne-cm (GREELEY).

In an attempt to isolate the dependence of the tectonic release on yield or explosion size, the moments were plotted against the world-wide average $a b$ ampli- 
tude of the short-period $P$ waves (taken from Lay et al., 1984) in Figure 10. Each $a b$ amplitude is based on all available WWSSN and CSN records in the distance range of $25^{\circ}$ to $95^{\circ}$. The instrument gains were equalized to unity at one second period, and geometric spreading corrections were applied to equalize the data to $50^{\circ}$. The relative size of each event can be determined by using a master event and normalizing the average amplitude by the master event amplitude. We chose BOXCAR as the master event (average $a b$ amplitude is $495 \mathrm{~m} \mu$ based on 48 stations). For the 21 events, HANDLEY has the largest relative $a b$ amplitude (1.41) while PIPKIN is the smallest (0.16). Although the size of the relative $a b$ amplitudes does not amount to a direct conversion to yield, we use it instead of published values for yields because it does not require an explicit formulation relating yield to $m_{b}$ or $M_{S}$.

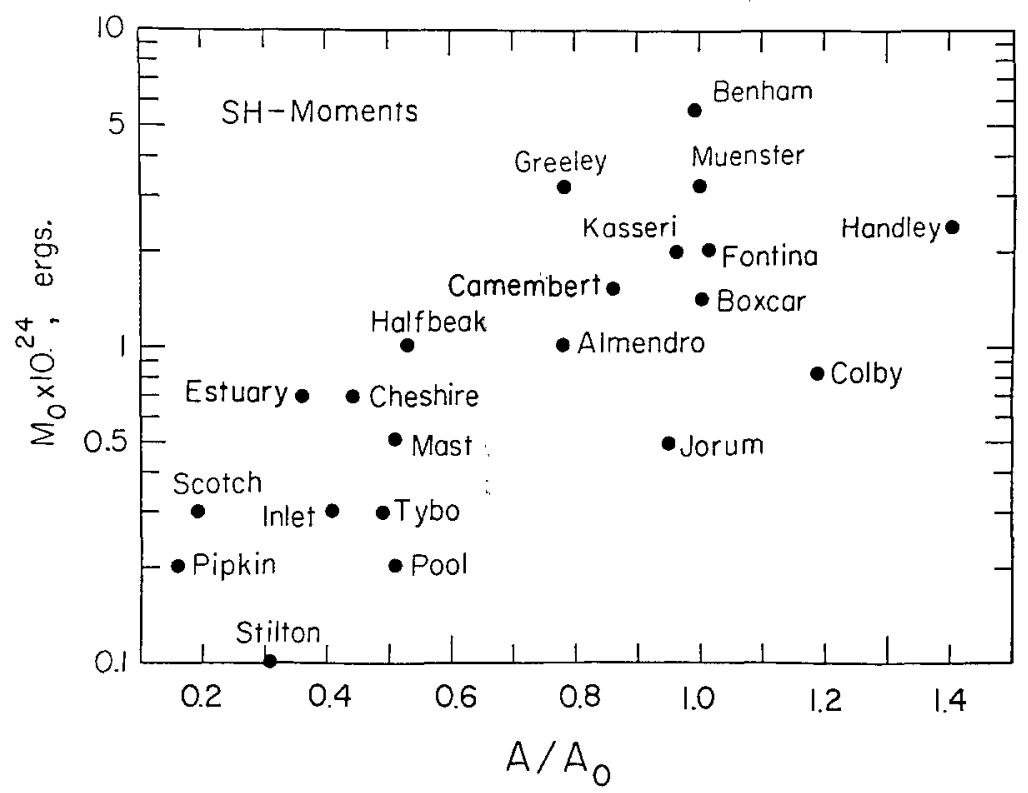

FIG. 10. The seismic moment of the tectonic release for 21 Pahute Mesa explosions plotted against average $a b$ amplitude. The amplitudes have been normalized to the average value for BOXCAR.

From Figure 10, it is clear that although the size of the tectonic release increases with the size of the explosion there are significant exceptions. For example, BOXCAR and JORUM are juxtaposed in the western part of Silent Valley Caldera, are about the same size, yet BOXCAR has a tectonic release moment which is three times larger than JORUM. Similarly, MAST has half the am amplitude of JORUM but the same tectonic release moment. In an earlier paper (Wallace et al., 1983), we suggested that tectonic release was significantly reduced when an event is detonated within 4 or $5 \mathrm{~km}$ radius from the location of a previous large explosion. To test this hypothesis, the Pahute Mesa explosions were separated into two populations: (1) those events which are well separated $(>4 \mathrm{~km}$ ) from previous events, and (2) those which are near $(<4 \mathrm{~km})$ a previous explosion. For simplicity, the first group of explosions are referred to as "isolated," and second group is referred to as "influenced." Figure 11 is a repeat of Figure 10 with the isolated events marked with an " $\mathrm{H}$," and the influenced events are indicated with an "L." It would be predicted that the isolated events would have a larger tectonic release moment than the sprung events. On the basis of Figure 11, it is clear that there is a separation of the " $\mathrm{H}$ " and "L" populations. A least-squares fit of seismic moment to $A / A_{0}$ for each 
population is also shown in Figure 11; the lines are nearly parallel but offset. STILTON and HANDLEY were excluded from the analysis. Both of these events seem to belong to the low tectonic release population, but they are relatively isolated implying that they should have high tectonic release. These two events are the only significant exceptions to the hypothesis that the tectonic release is associated with a volume of material which is several cubic kilometers, and explosions which have overlapping volumes will show a decrease in tectonic release for the later event. STILTON and HANDLEY are also the only Pahute Mesa explosions studied which are not located within Silent Valley Caldera. Although this may be coincidental, it is plausible that there is a different strain regime outside the Caldera and therefore the exclusion of STILTON and HANDLEY from the analysis is justified.

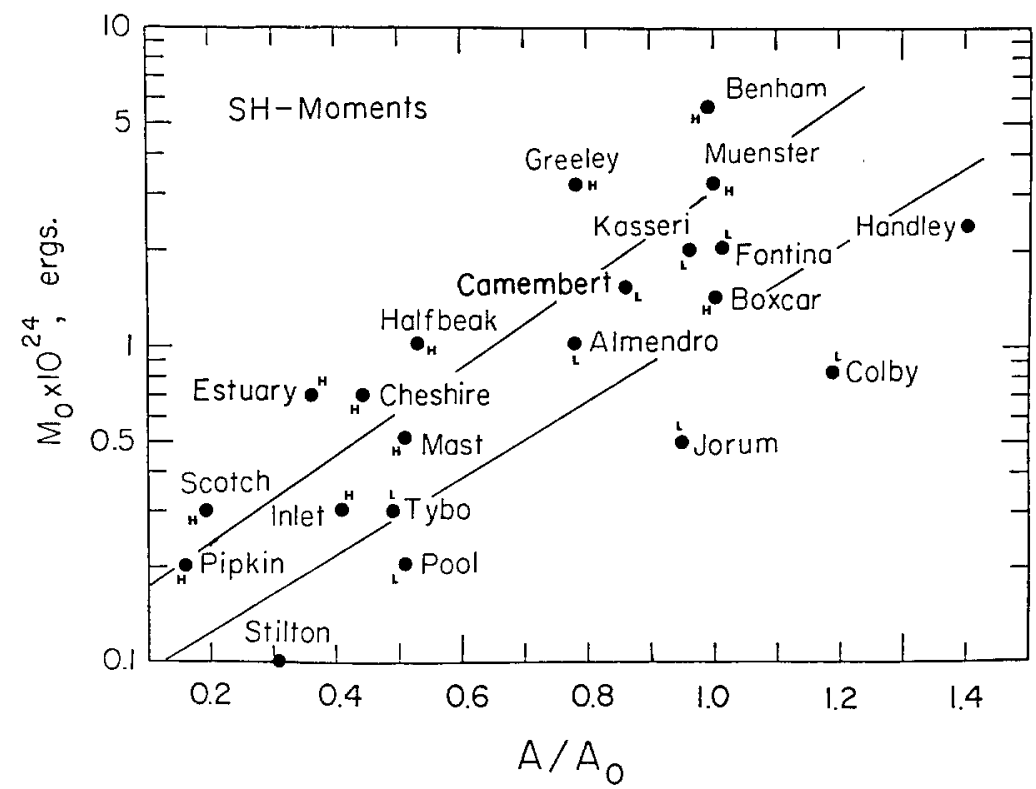

FIG. 11. The moment of tectonic release for the Pahute Mesa events plotted against the average $a b$ amplitude. The explosions have been divided into two populations: (1) those which are "isolated" and are predicted to have high tectonic release (labeled $\mathrm{H}$ ), and (2) those which are close to a previous explosion and should have low tectonic release (labeled L).

The fact that there is a separation of the isolated and influenced populations down to small sizes (PIPKIN probably has a yield which is less than $150 \mathrm{kt}$ ) indicates that there does not appear to be size threshold, below which no tectonic release is observed. Aki and Tsai (1972) found that for Yucca Flat events there was a size threshold and that in general this threshold increased in time. In the case of Pahute Mesa there is not a systematic decrease in tectonic release with time except when an event is located close to a previous explosion. This seems to imply that tectonic release is associated with a volume of material; the volume is related to the size of the explosion. On the basis of the $S H$ waves alone it is impossible to determine the actual source process of the tectonic release. The volumes appear to be larger than Archambeau's (1972) "crushed" zone, yet too small to be simple triggering on a single through going fault (Aki and Tsai, 1972). We prefer a model in which there is movement on a series of small faults or joints which is controlled by the regional stress regime. 


\section{CONCLUSIONS}

The tectonic release associated with Pahute Mesa explosions can be systematically modeled with an equivalent double-couple which is principally a strike-slip source. The $S H$ waves from the 21 different explosions were very similar, and the fact that the waveforms are reproducing strongly suggest that the tectonic release is an expression of a regional stress regime. Although there is some variation in the tectonic release double-couple, the "average" orientation is a right-lateral strikeslip fault trending $\mathrm{N} 15^{\circ} \mathrm{W}$. The use of waveform modeling and the polarities of $s P$ and $S V$ make it possible to resolve the classic ambiguity with using Love or $S H$ waves, and reject the $45^{\circ}$ dip-slip orientation. The extremes in the fault parameters are: (1) strike $\mathrm{N} 20^{\circ} \mathrm{W}$ to $\mathrm{N} 0^{\circ} \mathrm{E}$; (2) dip from vertical to $70^{\circ}$; and (3) the rake can vary from $160^{\circ}$ to $200^{\circ}$. The seismic moments associated with the tectonic release scale with the size of the explosion, but most importantly, the size of the tectonic release can be affected by the position of the explosion relative to location of previous large explosions. The explosions appear to separate into two populations: (1) "isolated" events which are well separated from other explosions, and (2) "influenced" events, or the explosions which are close to a previous explosion. The isolated events have much larger tectonic release associated with them than do the influenced events. A least-squares fit of the moment to event size on both populations indicates parallel but offset trends.

The fact that the best parameter for separating low and high tectonic release events appears to be a spatial position favors a volume model for the tectonic release. The volume depends on the size of the explosion. The best model for the source of the tectonic release would apparently be a distributed network of joints and faults that are driven by the explosions.

\section{ACKNOWLEDGMENTS}

We wish to thank T. Lay and L. Burdick for useful discussions and comments on this manuscript. T. Lay provided the basis for Figure 5. This research was supported the Advanced Research Projects Agency of the Department of Defense and was monitored by the Air Force Office of Scientific Research under Contract F49620-83-0025.

\section{REFERENCES}

Aki, K. and Y. B. Tsai (1972). Mechanism of Love wave excitation by explosive sources, J. Geophys. Res. 77, 1452-1475.

Aki, K., Reasenberg, T. DeFazio, and Y. Tsai (1969). Near-field and far-field evidences for triggering of an earthquake by the BENHAM explosion, Bull. Seism. Soc. Am. 59, 2197.

Archambeau, C. B. (1972). The theory of stress wave radiation from explosions in prestressed media, Geophys. J. 29, 329-366.

Bache, T. C. (1976). The effect of tectonic stress release on explosion $P$-wave signatures, Bull. Seism. Soc. Am. 66, 1441-1457.

Brune, J. N. and P. W. Pomeroy (1963). Surface wave radiation patterns for underground nuclear explosions and small-magnitude earthquakes, J. Geophys. Res. 68, 5005-5028.

Burdick, L. J. (1977). Broad-band seismic studies of body waves, Ph.D. Thesis, California Institute of Technology, Pasadena, California.

Dziewonski, A. M., J. E. Franzen, and J. H. Woodhouse (1984). Centroid-moment tensor solutions for July-September, 1983, Phys. Earth. Planet. Interiors (in press).

Dahlman, O. and H. Israelson (1977). Monitoring Underground Nuclear Explosions, Elsevier Press, New York.

Fisher, F., P. Papanek, and R. Hamilton (1972). The Massachusetts Mountain earthquake of 5 August 1971 and its aftershocks, Nevada Test Site, U.S. Geol. Surv. Rept. 474-149.

Hamilton, R. M. and J. H. Healy (1969). Aftershocks of the BENHAM nuclear explosion, Bull. Seism. Soc. Am. 59, 2271-2281. 
Hirasawa, T. (1971). Radiation patterns of $S$ waves from underground nuclear explosions, J. Geophys. Res. 76, 6550-6454.

Hutton, L. K., C. E. Johnson, J. C. Pechmann, J. E. Ebel, G. W. Given, D. M. Cole, and P. T. German (1980). Epicentral locations for the Homestead Valley earthquake sequences, March 15, 1976, Calif. Geol. 33, 60-67.

Langston, C. A. and D. V. Helmberger (1975). A procedure for modelling shallow dislocation sources, Geophys. J. 42, 117-130.

Lay, T., T. C. Wallace, and D. V. Helmberger (1984). The effects of tectonic release on short-period $P$ waves from NTS explosions, Bull. Seism. Soc. Am. 74, 819-842.

Murphy, J. R., C. B. Archambeau, and H. K. Shah (1983). Magnitude/yield variability in the western United States: Analysis of the Rulison/Gasbuggy anomaly, Final Technical Report, SSS-R-83-5978, S-Cubed, La Jolla, California.

Nuttli, O. W. (1969). Travel times and amplitudes of $S$ waves from nuclear explosions in Nevada, Bull. Seism. Soc. Am. 59, 385-398.

Patton, H. J. (1982). Measurements of Rayleigh-wave phase velocities in Nevada: implications for explosion sources and the Massachusetts Mountain earthquake, Bull. Seism. Soc. Am. 72, 13291349.

Press, F. and C. Archambeau (1962). Release of tectonic strain by underground nuclear explosions, $J$. Geophys. Res. 67, 337-343.

Ryall, A. and W. U. Savage (1969). A comparison of seismological effects for the Nevada underground test BOXCAR with natural earthquakes in the Nevada region, J. Geophys. Res. 74, 4281-4289.

Stein , R. and M. Lisowski (1983). The 1979 Homestead Valley earthquake sequence, California: control of aftershock and postseismic deformation, J. Geophys. Res. 76, 6477-6490.

Toksöz, M. N. and H. H. Kehrer (1972). Tectonic strain release by underground nuclear explosions and its effect on seismic discrimination, Geophys. J. 31, 141-161.

Von Seggern, D. (1970). The effects of radiation pattern on magnitude estimates, Bull. Seism. Soc. Am. 60, 503-516.

Wallace, T. C. and D. V. Helmberger (1982). Determining source parameters of moderate-sized earthquakes from regional waveforms, Phys. Earth Planet. Interiors 30, 185-196.

Wallace, T. C., D. V. Helmberger, and G. R. Engen (1983). Evidence for tectonic release from underground nuclear explosions in long-period $P$ waves, Bull. Seism. Soc. Am. 73, 326-346.

DEPARTMENT OF GEOSCIENCES

UNIVERSITY OF ARIZONA

TuCsON, ARIZONA 85721
SeISMological Laboratory

California Institute of TeChNology

Pasadena, CALIFORNia 91125

CONTRIBUTION No. 4100

Manuscript received 4 June 1984

\section{APPENDIX}

A moderate-size earthquake $\left(M_{L}=5.2\right.$ Caltech, $m_{b}=5.5$ NEIS) occurred on 15 March 1979 (UTC 21:07) northeast of Banning Pass $\left(34.371^{\circ} \mathrm{N}, 116.450^{\circ} \mathrm{W}\right.$ ) in Homestead Valley, California. The earthquake was the largest in a sequence of four shocks, about the same size, during a 4-hr period. The main sequence was followed by prolonged aftershock activity. Hutton et al. (1980) determined the focal depth to be $2.5 \mathrm{~km}$. The fault plane solution is well constrained on the basis of local shortperiod first motions (see Figure A1) and shows right-lateral motion on a northsouth plane.

The Homestead Valley earthquake produced good long-period regional distance waveforms at four WWSSN stations. Using the crustal model and technique described in Wallace et al. (1981), it is possible to invert these waveforms to obtain a source mechanism; the resulting inversion gave a mechanism which is nearly identical with the short-period first motions. Figure A1 shows a comparsion of the 


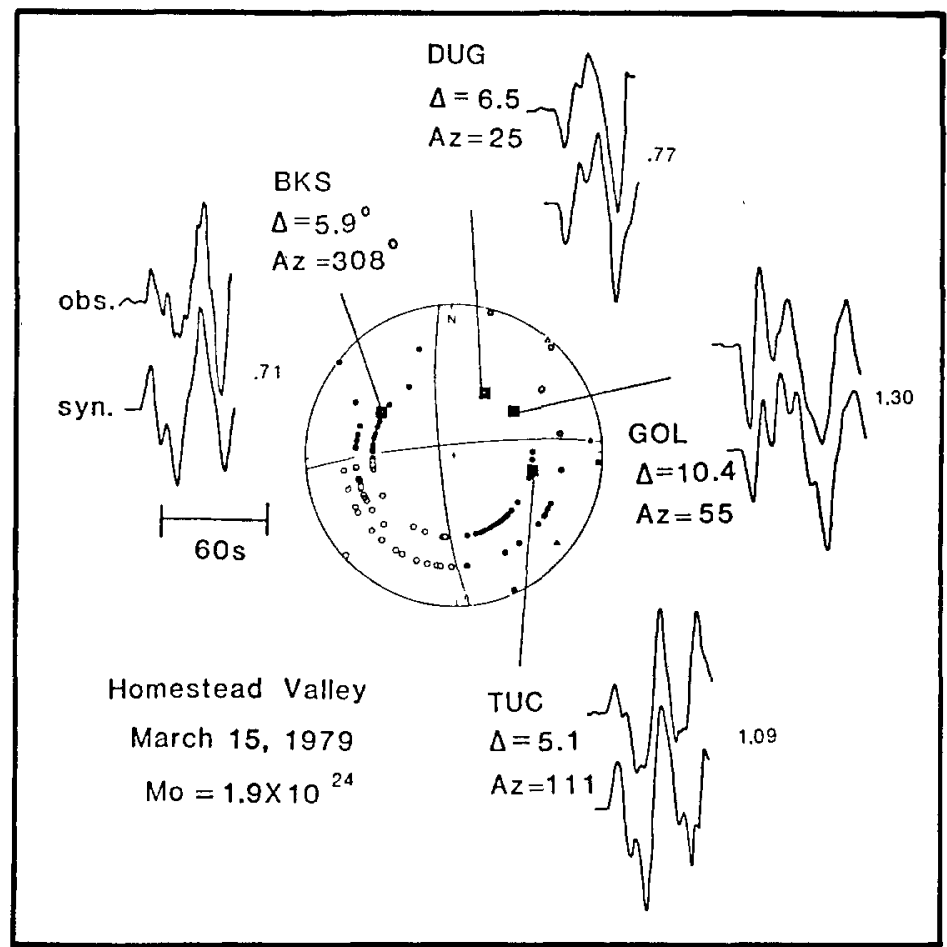

Fig. A1. A comparison of the observed (top trace) and synthetic (bottom trace) $P_{n e}$ waveforms recorded for the 15 March 1979 Homestead Valley earthquake. The numbers to the right of each seismogram pair give the ratio of the station to average moment.

vertical $P_{n e}$ observations and the synthetics which were computed for the inversion source. The moment of the earthquake can be determined by comparing the amplitude of the observations and synthetics. The average moment was found to be $1.9 \times 10^{24}$ dyne-cm. This value is in close agreement with Dziewonski et al. (1984) who determined a moment of $2.2 \times 10^{24}$ dyne-cm from the inversion of 40 - to 80 sec period mantle waves. Stein and Lisowski (1983) determined a moment of $4.2 \times$ $10^{24}$ dyne-cm for the entire earthquake sequence on the basis of geodetically measured fault slip. On the basis of the sizes of the four events in the main shock sequence $\left(M_{L}=4.9,5.2,4.5,4.8\right)$, the value determined for the moment of the $M_{L}$ $=5.2$ shock is excellent agreement with the static measurements. The ratio of the moment determined from each seismogram to the average moment is shown to the right of each trace in Figure A1. 